Article

\title{
Friend, Foe or Frenemy? Traditional Journalism Actors' Changing Attitudes towards Peripheral Players and Their Innovations
}

\author{
Sherwin Chua ${ }^{1, *}$ and Andrew Duffy ${ }^{2}$ \\ ${ }^{1}$ Department of Journalism, Media and Communication, University of Gothenburg, 40530 Gothenburg, Sweden; \\ E-Mail: sherwin.chua@jmg.gu.se \\ 2 Wee Kim Wee School of Communication and Information, Nanyang Technological University, 637718 Singapore, \\ Singapore; E-Mail: duffy@ntu.edu.sg \\ * Corresponding author
}

Submitted: 15 June 2019 | Accepted: 15 October 2019 | Published: 17 December 2019

\begin{abstract}
This study synthesises two analytical frameworks - journalistic strangers and agents of media innovation-to examine how perceptions among newsworkers towards new entrants to their field shape the normalisation of innovations in a digitalfirst legacy news organisation over three years. Based on two rounds of interviews, it finds that peripheral players are gradually recognised for their contributions to journalism by traditional actors. Nonetheless, as barriers between the two groups lower, tensions involving dissonant professional perspectives, practices, and jurisdictions surface and are negotiated. The findings indicate a growing salience of hybrid roles in newsrooms that serve as linchpins to connect divergent professional fields, and more importantly, as bridges between tradition and innovation. Based on the increasing importance of collaboration and hybrid roles, this study makes a theoretical and practical contribution to research and media management by proposing that four forms of proximity-physical, temporal, professional, and control-are crucial in operationalising the impact that peripheral players have on innovation in news organisations.
\end{abstract}

\section{Keywords}

appropriation of innovation; interlopers; journalism; media innovation; peripheral players

\section{Issue}

This article is part of the issue "Peripheral Actors in Journalism: Agents of Change in Journalism Culture and Practice" edited by Avery E. Holton (University of Utah, USA), Valerie Belair-Gagnon (University of Minnesota-Twin Cities, USA), and Oscar Westlund (Oslo Metropolitan University, Norway / Volda University College, Norway / University of Gothenburg, Sweden).

(C) 2019 by the authors; licensee Cogitatio (Lisbon, Portugal). This article is licensed under a Creative Commons Attribution 4.0 International License (CC BY).

\section{Introduction}

Peripheral players in news-actors and organisations that include bloggers, citizen journalists, web programmers, and digital analytics companies who are not commonly associated with journalism (Holton \& BelairGagnon, 2018; Tandoc \& Oh, 2017)-have the potential to simultaneously contribute to the evolution of journalism and to disrupt its boundaries. At a time when news organisations face the challenges of declining revenues and audience figures, coupled with an increasing strain on production and operations (Nielsen, Cornia, \&
Kalogeropoulos, 2016), news organisations are increasingly pressured to innovate (Posetti, 2018). Thus, the role of peripheral players in newsroom innovation becomes crucial to assess. Earlier studies have observed that how innovation is accepted into everyday practice depends on whether it comes from traditional or peripheral players, or from inside or outside news organisations (e.g., Eldridge, 2018; Holton \& Belair-Gagnon, 2018; Lowrey, 2012; Lowrey \& Gade, 2012). Similarly, media scholars have paid attention to the transforming tensions and negotiations surrounding diverse social actors involved in co-shaping innovation activities 
(e.g., Baack, 2018; Krumsvik, Milan, Bhroin, \& Storsul, 2019; Westlund, 2011; Westlund \& Lewis, 2014), including how news organisations increasingly engage in crossfunctional collaboration that involves journalists and peripheral players such as technologists and commercial managers (Cornia, Sehl, \& Nielsen, 2018; Nielsen, 2012). Yet, to our best knowledge, few journalism studies to date trace over time how traditional journalism actors perceive the role of peripheral players in shaping innovation (exceptions include MacGregor, 2014; Micó, Masip, \& Domingo, 2013; Westlund \& Krumsvik, 2014).

This article addresses this gap by examining over a three-year period how the perceptions of traditional journalism actors (referred to as 'newsworkers') towards peripheral players shape the appropriation of innovations in a digital-first legacy news organisation in Singapore. In the context of this study, we refer to innovation as change in news organisations pertaining to new media technologies and practices that involve complex social interactions which can shape communication and relationships between actors (Westlund \& Lewis, 2014), and appropriation of innovations as the process by which social actors adopt, adapt, and integrate innovations into everyday practices (Carroll, Howard, Peck, \& Murphy, 2003). We argue that studying the attitudes of newsworkers towards peripheral players over time is theoretically and practically important in order to shed light on how innovations are appropriated and can guide news organisations to better adapt to the changing news ecosystem, which ultimately impacts on the future of journalism and its role in society (Pavlik, 2013). Furthermore, a holistic understanding of innovation appropriation processes in organisations requires long-term approaches as innovations do not remain stagnant but are iteratively transformed throughout the innovation process (Slappendel, 1996). This study includes two rounds of semi-structured in-depth interviews with 20 newsroom staff, comprising mostly journalists but also technologists and commercial managers at a legacy news organisation in Singapore collected at two different points in time-between end-2015 and mid-2016, and again from end-2018 to early-2019.

This article is organised into six sections. The second section discusses the literature in relation to the role of peripheral players in shaping innovations in news organisations. The third section outlines our analytical frameworks which are based on the typology of strangers (Holton \& Belair-Gagnon, 2018) and the agents of media innovation (AMI; Westlund \& Lewis, 2014). The fourth section explains our methodological considerations for our case study, while the fifth presents our findings that explore how changing perceptions of newsworkers towards peripheral players over time have influenced the appropriation of innovations. The discussion and conclusion section includes a theoretical and practical contribution in the form of proximity of peripheral players as a key factor in understanding innovation appropriation in news organisations.

\section{Peripheral Players and Innovation in News Organisations}

There has been growing interest in the role of peripheral players inside and outside news organisations in shaping how innovations are appropriated. From an outsidein perspective, researchers have assessed the impact of "exogeneous influences" (Krumsvik et al., 2019, p. 198) such as audiences and technology-related advances on innovation in news organisations. For example, Singer (2005) observes that the ubiquity of blogs has influenced their normalisation among newsworkers, noting that traditional journalists are not just gatekeepers of information but also of innovation. This shaping of innovation in news organisations by external forces is also illustrated by Krumsvik (2018) in his longitudinal study of Norwegian newsrooms. He argues that changes in audiences' digital news habits have influenced news companies to alter their approaches towards their users from being co-producers to distributors of news.

Looking inside news organisations, meanwhile, scholars have argued for the importance of understanding the role that interactions, interrelationships, and tensions among traditional and peripheral journalism actors play in shaping innovation (e.g., Steensen, 2009; Westlund, 2011; Westlund \& Lewis, 2014). Nielsen (2012) examined collaboration between technologists, journalists, and managers in two newspapers developing blogging capabilities, and posits that the dynamics between members of communities may be analysed as either enablers or disablers of innovation. In a case study assessing the appropriation of emerging technology in legacy news organisations and digital news start-ups, Chua and Westlund (2019) opine that as digital innovation becomes increasingly important to the economic considerations of news publishers, they seek new ways to create environments that foster cross-departmental collaboration and innovation. Yet organisations tend to resist innovation rather than embrace it (Utterback, 2004), and journalists have historically been defensive of their traditions (Mitchelstein \& Boczkowski, 2009).

More recently, as the boundaries between traditional and non-traditional journalism blur, researchers have underscored the inadequacy of the insider/outsider distinction, and turned their attention towards how the interplay between traditional actors at the core and nontraditional players at the periphery shapes the manner in which journalists innovate (Eldridge, 2018; Holton \& Belair-Gagnon, 2018). For instance, Lewis and Usher (2013) examined boundary negotiations in the case of collaborations between traditional journalists and hackers, and argue that such partnerships possess the potential to "reinvigorate newswork" (Lewis \& Usher, 2013, p. 614) and introduce innovations that make journalism more relevant in the digital era. Similarly, Baack (2018, p. 676) studied the "interlocking practices" of data journalists and civic technologists and found that despite having distinct professional backgrounds, the overlap in 
their skills and aspirations contributed to the forging of a complementary relationship, giving rise to novel practices in both professions. In a study of web analytics company managers' influence on the adoption of analytics in news production, Belair-Gagnon and Holton (2018) found that managers, as peripheral players, subtly introduce innovations in the news process through the adoption of web analytics by strategically positioning themselves as collaborators who acknowledge that their own companies' success is closely tied with the success of journalism, but who have no intention of driving cultural or institutional change among journalists. Focusing on digital journalists, Vos and Ferrucci (2018) highlight that although online reporters set themselves apart from citizen journalists, bloggers, and professional journalists working in traditional media, their professional identities have been influenced by both traditional and peripheral players.

\section{Analytical Framework}

Building upon this literature, this study seeks to understand how newsworkers' attitudes towards peripheral players shape the appropriation of innovation in a digitalfirst legacy news organisation. This study is guided by a synthesis of two analytical frameworks: the typology of strangers in journalism proposed by Holton and BelairGagnon (2018) and the AMI developed by Westlund and Lewis (2014).

\subsection{Strangers in Journalism}

Arguing for a more systematic approach towards examining peripheral players and their roles in challenging boundaries, epistemologies, discourses, and the practice of journalism, Holton and Belair-Gagnon's (2018) typology of journalistic strangers identifies three groups of non-traditional journalism actors. First are the 'explicit interlopers,' who are non-traditional actors operating outside the news organisation and not defined as journalists (physically distant, professionally proximate). They may not be welcomed by mainstream journalists, but they directly contribute content or products related to the production and distribution of news. They tend to be early adopters of innovations, and consistently challenge journalism norms and practices. This group includes bloggers and citizen journalists. Second are 'implicit interlopers,' who are non-traditional actors who work outside the news organisation (physically and professionally distant) and whose technological contributions, such as better tools to advance content production, news dissemination, and audience engagement are valued by traditional journalists. This group includes programmers and web analytics professionals (cf. Tandoc \& Thomas, 2015). Third are 'intralopers,' who are non-traditional journalistic actors who offer their expertise from within news organisations and are thus "less strangers by proximity than they are by the work they perform in relation to news production" (Holton \& Belair-Gagnon, 2018, p. 75). They are physically proximate but professionally distant. This group includes all non-editorial workers whose functions supplement and/or complement journalistic work. Applied to our study, this framework guides examination of how newsworkers' attitudes towards these three groups of peripheral players have changed over time.

\subsection{Agents of Media Innovation}

While the typology of strangers guides our understanding of newsworkers' perceptions towards peripheral players, the AMI framework (Westlund \& Lewis, 2014) focuses our analysis on how innovations are appropriated in news organisations in relation to who potentially drives these innovative activities. The AMI theorises that innovation involves complex interactions among, and may be driven by, diverse agents referred to as the three As: (i) 'Actors'-all humans such as journalists, technologists, and businesspeople working in media organisations and who are potentially involved in innovation, although it may entail actors from outside the organisation who can influence processes within the firm; (ii) 'actants' - non-human technologies that are appropriated in media work and offer enabling and disabling affordances in the context of innovation; and (iii) 'audiences'-end-users who receive media products and services, but in the way that actors within news organisations think of audiences as either passive receivers of news, commodities for advertisers, or as active participants in the news production process. Importantly, in examining the drivers of innovation processes in organisations, the AMI's authors stress the value of scrutinising "perceptions and behaviours of, and cooperation among, all of the organisational actors potentially involved in innovation" (Westlund \& Lewis, 2014, p. 17). In relation to our study, this framework underscores the importance of a holistic perspective that takes into account not only the interactions between journalists and peripheral players, but also among audiences and technological actants.

\subsection{Synthesis and Study Rationale}

Media scholars note that journalists do not work in a vacuum, and increasingly examine how peripheral players influence innovation, as this has both theoretical and practical implications (e.g., Paulussen, 2016; Schmitz Weiss \& Domingo, 2010; Waldenström, Wiik, \& Andersson, 2019). To date, however, few studies have analysed the relationship between the perceptions of traditional journalism actors towards peripheral players and the appropriation of innovation in news organisations. To this end, this study synthesises the typology of strangers and AMI frameworks to analyse how changes in newsworkers' attitudes towards 'outside' players over time shapes innovation appropriation, and asks these research questions: 
RQ1: How did newsworkers' attitudes towards peripheral players' and their innovations change between 2015-2016 and 2018-2019?

RQ2: How is innovation driven by peripheral players appropriated in the legacy news organisation?

\section{Method and Material}

Case study is an optimal method for examining contemporary phenomena in their real-life context (Yin, 2018). This study is based on ethnographic data collected from the Straits Times (ST), a digital-first legacy news organisation in Singapore, at two different points in time: Between end-2015 and mid-2016, and from end-2018 to early-2019. ST represents a theoretically informed case study that typifies the empirical phenomenon the research is interested in (Rule \& John, 2015). ST was founded in 1845 and employs about 300 staff. It is Singapore's most-read English broadsheet newspaper and had, until 2017, a market capitalisation larger than that of the New York Times Company (Yap, 2017). Both its advertising revenues and circulation have both since fallen, as seen also in many newspapers in other countries. As a counter to this, ST has attempted to transform itself from a print-focused newspaper to a digitalfirst news organisation and has been innovating its digital news since 2013 (Chua \& Westlund, 2019).

The 2015-2016 data in this study included newsroom observations and semi-structured, in-depth interviews for two separate studies (Chua \& Westlund, 2019; Duffy, Tandoc, \& Ling, 2018) that examined emerging technology in ST. Subsequently in 2018-2019, both this study's authors again interviewed ST staff in their offices, over the phone, and via Skype, asking questions from an interview guide that had been jointly prepared by both researchers. The questions were built on observations from the 2015-2016 research and based on the typology of journalistic strangers and the AMI frameworks. Interviews were semi-structured to allow for thematic clustering of responses and to allow space for an emotional dimension to emerge (Fontana \& Frey, 2005). Despite being distinct in focus, both studies in 2015-2016 partly involved examining newsworkers attitudes towards peripheral players vis-à-vis digital innovation, and hence included compatible features. This overlap made portions of the 2015-2016 data from each study suitable for comparison with the data collected in 2018-2019 to examine how newsworkers' perceptions towards peripheral players changed over time and plays into how it shapes innovation. In all, this study comprises interviews with 20 staff, with 10 during each round of data collection. These staff were mostly newsworkers (senior editors, newspaper reporters, video journalists, digital journalists, and sub-editors), but also included selected technologists and business managers who have worked directly with newsworkers to give multiple viewpoints (cf. Lewis \& Westlund, 2015; Westlund \& Lewis,
2014). Although this study is an extension of earlier research in the same news organisation, it does not claim to be longitudinal because most people interviewed and questions asked differed between 2015-2016 and 2018-2019.

All interviews were done under conditions of anonymity as a "a key principle is to respect the privacy of those you study" (Babbie, 2011, p. 444), so the names have been changed here and the job titles are representative of what they do but do not allow for identification. This was done in order to give interviewees freedom to speak openly about attitudes towards colleagues, whether proximal or peripheral. While interviewees in the 2015-2016 round made passing reference to peripheral players, that phrase had not yet been coined; it emerged in scholarship in 2018 and was employed to drive the second round of interviews and formed the core of the questions.

For data analysis, this study's authors independently reviewed their 2015-2016 ethnographic data, including field notes and interview transcripts, and thematically coded relevant sections to highlight newsworkers' attitudes towards peripheral players. The same was done for the 2018-2019 interview data. Thereafter, both researchers combined their individual analysis from both phases of data collection and iteratively discussed as well as assessed the data for emergent and recurring patterns in relation to newsworkers' shifting attitudes towards peripheral players and their implications on innovation appropriation within ST. The data analysis therefore took an inductive approach (Polit \& Beck, 2003) of immersion in the interview transcripts to identify themes among answers and the quotes below are instances where both researchers agreed that a theme was evident and the exemplar was representative.

\section{Findings}

\subsection{Newsworkers' Attitudinal Changes over Time}

The first research question asked what changes in attitudes by newsworkers towards peripheral players in ST could be observed between 2015-2016 and 2018-2019, and we present the findings using Holton and BelairGagnon's (2018) typology of strangers. Explicit interlopers are outsiders because of where they stand, but insiders because of what they do (physically distant, professionally proximate). They include bloggers and citizen journalists who are clearly outside the newsroom. The 2015-2016 ethnographies saw few references to explicit interlopers, which may indicate that the boundaries of the newsroom were tightly patrolled and outside voices discouraged. Richard, a social media editor, said in 2015-2016 he read tech blogs to stay well informed; other than that, no one mentioned them. The role of citizen journalism was to be confirmed by traditional journalism, as Richard said: "People share with us photos of fire, accidents, or even send in rumours to 
ask if it is legit or not since people still believe in ST'S credibility." Gary, a digital editor, meanwhile, grudgingly said: "There is value in citizen journalism but it is overrated. A lot of people do not understand how journalism works." In 2018-2019, by contrast, explicit interlopers were characterised as a strength by newsworkers. Firstly, they are not constrained by newsroom norms and ideologies. A section editor, Nicholas, said: "They occupy a space we aren't in." Their value lies in this separation: "They bring value in terms of voicing views that either we don't subscribe to, or even if we agree with some of the points, we may not put them in the way they do." Secondly, as they are not constrained by newsroom norms, explicit interlopers can innovate, which makes them a source of inspiration. Aurora, a reporter, saw bloggers as a group to watch closely as these explicit interlopers have a separate skillset from traditional journalists whom she thinks journalists could "learn more from" and that the ST newsroom "could do with more of their influence here." Thirdly, content produced by explicit interlopers has value because, as outsiders, they cover events which reporters cannot, but their content is quickly normalised into newsroom processes. Susannah, a reporter, said that eyewitness photographs might be used in early online versions of a story, but are quickly replaced by pictures from in-house photographers sent to the scene.

Implicit interlopers, who include external programmers, web developers and analysts, are also outside the newsroom and what they do is not directly related to newsgathering, making them physically and professionally distant. However, they possess skills and knowledge that may offer contributions that can improve journalism and hence are valued by traditional newsworkers. In 2015-2016, while amateurs from outside the newsroom were disdained, experts were in demand:

We try to organise lunchtime talks when there are experts in the region who are passing through Singapore, just to talk to the reporters, people in the newsroom, but the broad areas would be things like product, analytics, and innovation. (Gary, digital editor)

By contrast, Richard (social media editor) expressed caution about his meeting with implicit interlopers from beyond the newsroom: "I met some of the Twitter folk. So, one of my responsibilities, sort of, is also a bit on partnership with the tech and social media companies," where the equivocation of "sort of" and "a bit" alongside the diminutive term "folk" suggests caution. In 2018-2019, implicit interlopers were more in evidence than explicit. At one level, traditional newsworkers recognised their necessity in a time of change. Gary (digital editor) said: "We're starting to learn how to use data, but we need quite a bit of hand-holding." Richard (social media editor) added that he frequently consults web analytics companies and external data specialists on improving $S T^{\prime}$ 's an- alytics capabilities. The relationship is characterised as newsroom workers needing guidance from respected implicit interlopers. But at another level, these peripheral players were still characterised as separate, physically and professionally, and engagements with them still warranted caution, as Gary (digital editor) explained: "I think they're [technology and social media companies] are our frenemies.... can cite numerous times when they talk about how they are valuable to us. Yes, to some extent, but in most cases, no!"

Intralopers, meanwhile, are inside the newsroom but the work they do is not directly journalistic (physically proximate but professionally distant). They include people working inside the organisation in non-traditional journalistic roles. In ST, coders and web developers are often in-house rather than being outsourced, and the value accorded to these intralopers appeared to be connected to their physical proximity. Gary (digital editor) explained in 2015-2016 he had to convince HR to hire one coder to be seated in the newsroom just so the digital news team did not have to "get the IT department guy to come up.... He doesn't understand news-he's a tech guy." Similarly, given a shift towards producing news stories in video format for apps, websites, and smartphones, "when Gary wanted a video unit under ST's digital desk, we came down-we were upstairs before-and joined the ST newsroom," said Karen, a video team editor, in 2015-2016. Stephen, a video journalist on her team, added: "We were moved because we need to work closely with the ST editors and journalists when producing videos.... It's quite clear that they want us to be more integrated into the ST ecosystem."

In 2018-2019, intralopers in the form of video and interactive graphics teams were seen as extensions of journalistic practice and were increasingly integrated as the print product moved online. They were characterised in positive terms. Elspeth, a reporter, interacts frequently with the digital interactive graphics team: "I think there's a lot of respect in terms of we know that they know something we don't and likewise we know something they don't, so we try to, I guess, use our skills to complement each other." This led to the observation that intralopers who fit the traditional mould, even if their skills are not print-oriented, were treated as insiders, while coding intralopers were still outside the boundaries: "We still work very closely with video so they are like an extension of the team. But when it comes to web coders...those are very separate, at least for me, they are a separate group of people who manage things behind the scenes," said Aurora (reporter) before adding by way of a counterbalance: "They are really important, I just don't think I have enough interaction with them." Cognitively, she accepts that coders and web developers are crucial contributors, but emotionally and physically they are still at a distance. Similarly, the ST digital marketing department whose office was on another floor within the building were often characterised more as an absence than as a presence, as this quote from Nicholas (section editor) in 2018-2019 
shows: "I'm sure they're doing stuff, but I don't know what they're doing and how it affects our day-to-day stuff." Broadly, intralopers-particularly those who sit inside the newsroom-were more accepted than internal or external interlopers. This is also pragmatic: Both Lisa and Susannah, reporters interviewed in 2018-2019, said that if a closer relationship with commercial entities would keep valuable news flowing to people, and allow them to continue doing what they loved, then this was a trade worth making. Rather than a betrayal of journalistic principles, it was a "new normal" for the newsroom.

Despite increasing integration of intralopers in ST, a hierarchy that puts newsworkers above intralopers was observed. Web developer Wendy explained that "the standard procedure of how things work in the newsroom" often involved newsworkers taking the lead on innovation projects. Gary (digital editor) described it in terms of project ownership: "We are the product owners, whereas the product and tech guys are more the product managers." Nonetheless, he is open to others leading: "If it's editorial-led, yes, editorial will be the product owners; but sometimes if it's circulation-led or marketing-led then it' $d$ be another product owner where editorial plays a supporting role."

Other changes were structural (cf. Lowrey \& Gade, 2012). Communication flowed more easily between departments in 2018-2019 than in 2015-2016: "I used to create entire stories and graphics without ever speaking to a journalist who was working in that field...but now we don't do that anymore, which is really good. We work directly with them" (Charissa, interactive digital journalist, 2018-2019). The change is at the level of workplace culture, according to Imelda, a reporter: "Initially when I joined it was very strait-laced; there wasn't a lot of input you could have about how you wanted your story to look on a page, but now it's more of a dialogue." However, pockets of communication chasms remained despite a redesigned newsroom intended to encourage collaboration. Elspeth (reporter) said in 2018-2019: "The team [of coders] here, they kind of keep to themselves....I don't know if it's the nature of their job or they're just introverted by nature, but they're...different from journalists who are very talkative and opinionated."

On learning peripheral skills, both Richard (social media editor) and Nicholas (section editor), in 2015-2016, had noted how several colleagues were reluctant to master digital journalism skills. By contrast, ST's newsworkers in 2018-2019 acknowledged the importance of acquiring skills that the interlopers and intralopers possessed in order to adapt to the digital news environment. Imelda (reporter) added that old-school journalists saw the need to learn those skills-in particular, video skills. The effect, then, is of traditional journalists adopting new skills which make them non-traditional; which in turn alters the boundaries of what is traditional journalism, so that they, over time, become 'traditional' journalists once again. Additionally, reluctance on the part of the newsworkers to change creates the need for interlopers and intralopers to perform the tasks they are unwilling to do. Yet, as Imelda (reporter) said: “I don't think [we] have a choice. If we had stayed in the old ways, we'd be dead now."

Further, implicit interlopers and intralopers were often characterised in terms of a clash of professional cultures. Marketers and coders have different goals from reporters and editors. Looking at the commercial side first, Nicholas (section editor) in 2018-2019 acknowledged that declining advertising revenue may shift professional values and drive collaboration:

Every newspaper needs to adapt and work with the business side of the house. Ideally it shouldn't affect your editorial decisions, but there should be an understanding of what's going on and then look at how you can monetise your paper.

This sentence merits unpicking: First, Nicholas (section editor) distances himself from this commercial innovation by generalising the decision to "every newspaper"; the phrase "the business side" indicates that it is separate; the word "ideally" shows that such adaptation is a challenge to professional ideals; while the business term "monetise" may be considered at odds with traditional journalistic language. The peripheral player clashes with journalistic values; innovation is distanced from day-today practice, although Nicholas (section editor) adds that personally, he feels there should be greater collaboration with non-editorial departments in his daily work and it is important for him to do so.

Yet, when their professional goals converge, the working relationship between newsworkers and intralopers was characterised positively. Elspeth (reporter) in 2018-2019 feels that her relationship with coders "is more respectful because we are working together on a common product. They're not doing it for the money, they're doing it for a good product. But the marketing side has totally different goals." Innovation is thus integrated into newsroom activities when some greater principle is invoked beyond the immediate short-term goal. There is no need for practice to overlap; but peripheral players need to contribute to a core journalistic goal. Laura, a reporter, in 2018-2019 sees the video production team as "part of the gang, maybe because they don't chase stories themselves, but they are still part of the newsroom."

\subsection{Appropriation of Innovation}

The second research question asked how innovation was appropriated into newsroom activities, seen through the AMI framework of actors, actants, and audiences (Westlund \& Lewis, 2014). We start from actors inside the newsroom. First, management and senior editors drive innovation, but their suggestions are not always welcomed nor understood: "Ever since we had this report thing [ChartBeat], I've had a lot more suggestions from 
my supervisor on click-baity articles, and once I asked if this was the road we are going down and he said "yes"' (Laura, reporter, 2018-2019). She went on to say that her supervisors do not "understand" the meaning of digital: "He says 'I want you to go digital' and I say 'so what does that mean?' and it's like 'It's up to you what's digital'." Aurora (reporter) recounted a similar experience in 2018-2019:

They are asking you to think outside print, even though they don't really say what 'outside of print' they really want....I think that they are just making their way and trying to find something that works, and they expect us to come in and plug it for them.

Second, journalists approach non-traditional actors in the company to collaborate, but encounter a 'language gap.' Reporters said that web developers and coders do not understand what makes a story newsworthy, while coders said that reporters did not appreciate the realities of their working practice as seen in this comment from Wendy (web developer) in 2018-2019:

When it comes to innovation, the idea is initiated by our team and when we propose these ideas, we already took design thinking in mind, what kind of data structure we need to follow, what kind of content is more appropriate, the user experience. When the idea comes from the other teams...their way of thinking is more of making a piece more related to news angles. So that's a different strategy.

Elspeth (reporter) in 2018-2019 called for a new generation of "bridge" people who can connect these two sides, and is teaching herself coding, with mixed success. Charissa (interactive digital journalist) said in 2018-2019 she performs just such a role: "I'm bridging the gap between print and even your online stories to see how we can present them visually." One mechanism to achieve this is to bring teams together, so that the interactive digital journalists and the coders sit in the same space. Charissa (interactive digital journalist) added: "I think it's super-essential; they [coders] are listening to all the conversations that are going on about the stories."

Looking outside the newsroom, interviewees mentioned marketing and technological colleagues. Marketing is resisted even while interviewees recognise the need for commercial innovation. Nicholas (section editor) said in 2018-2019: "You need to think about marketing, and how the advertisers may react to certain things. It's not that it would change our position, but it's something you need to be sensitive about." As advertising revenue drops, he sees increased pressure while saying: "For me, honestly, I barely, almost never talk to marketing and so on." This extends to technological innovation, too. Like St Augustine praying for chastity-but not yet-Nicholas (section editor) appears reluctant to drive change while agreeing that it is needed: "I think at some point we need to think about how we can write or present the story and make best use of the online medium....at some point we need to slowly head in that direction." This sense of caution may be interpreted as one reason why innovation is likelier to come from outside the newsroom than from within; there is a strong path-dependency for long-serving newsworkers who acknowledge the need for innovation but do not feel driven to enact it themselves.

One 2018-2019 interviewee, Shereen, a commercial manager, integrated marketing and technology into a new initiative which saw her interacting with editorial who resisted this innovation: "There wasn't that much additional input from the editorial team about maybe creating content specifically for affiliate marketing...it was difficult to get commitment from the journalists....and around the editorial integrity part there is a little bit of hesitance." A changing environment is driving the need for innovation; her question is who should take charge of changes inside the news organisation. Shereen (commercial manager) observes a lack of willingness from the newsroom to take ownership of closer commercial collaboration: "They're, I guess, happy for you to try, but from an ownership point of view, not necessarily."

Analytics is a form of audience incursion into the newsroom as well as a technological interloper which influences journalistic decision-making. Based on the 2018-2019 responses, it has four impacts on the newsroom: Functional-“it helps us keep track of which stories are doing better" (Nicholas, section editor); personal- "it's a validation of what I do" (Laura, reporter); professional- "we are judged by these analytics" (Laura, reporter); and commercial- "you can see with your own eyes how we're making money for the company" (Aurora, reporter) as one metric is the number of conversions which is when a reader subscribes after reading an article. This is a significant innovation, because it draws a direct link between stories and revenue, changing the nature of the relationship between the individual news article and the business side of a newspaper. Analytics were also appropriated into newsgathering practice in innovative ways. Imelda (reporter) used the data from ChartBeat to persuade sources to speak to her; and to motivate public relations executives to give her access to celebrities:

I wrote a quick online story and it was one of the top trending stories for the past two days and it gave me leverage to go to the promoter and say it's doing so well, can you get me an interview with him [the celebrity] when he comes?

Nonetheless, Laura (reporter) said management seems to view a successful story as one that attracts clicks, but feels that articles which engage readers are "not the clickbaity stuff." Here, professional barriers between newsworkers and both the audience and the business side appear to become more porous. 


\section{Discussion and Conclusion}

This article examines what traditional journalism actors' attitudes towards peripheral players indicated about how innovation is appropriated in a digital-first legacy news organisation. It subscribes to the idea that outsiders have the benefit of not being encumbered by "the way we do things here" (Bruns, 2014).

With reference to the first research question, this study observes that over time the traditional newsworkers were gradually more accepting of peripheral players' innovations. Regarding explicit interlopers, the newsworkers' initial disdain towards bloggers and citizen journalists was replaced by acknowledgement of their value in representing alternative perspectives, although the newsworkers were quick to point out that these interlopers occupy a space that they do not. This is congruent with Vos and Ferrucci's (2018) argument that despite appearing to be less insular and more willing to recognise interloping actors, digital-first newsrooms still keep a professional distance from citizen journalists. The newsworkers also gradually recognised a pressing need to engage with external experts, especially those who were knowledgeable in digital news development and analytics, who they thought possessed the know-how to facilitate successful innovations, bringing them into their professional circle.

When discussing analytics as a technological interloper, newsworkers' original ambivalence gave way to largely enthusiastic responses that included novel ways of integrating reader metrics in news production such as using it as leverage to get interviews. In this sense, interlopers symbolise agents of change that simultaneously test and alter the identity of traditional journalism actors and their profession (Belair-Gagnon \& Holton, 2018; Eldridge, 2018). Likewise, when discussing intralopers, newsworkers were progressively more cognisant of the importance of collaboration between staff from editorial, business, and technology functions. The findings suggest that this awareness was influenced by the news organisation's efforts at introducing structural changes, such as formalising processes aimed at better inter-departmental cooperation and redesigning physical work-spaces to promote interaction. These synergies contributed to improving newsworkers' perceptions of peripheral players by drawing them closer professionally and physically.

With reference to the second research question, this study finds that in line with a growing body of research observing greater collaboration between editorial, commercial, and technological operations in newsrooms (Cornia et al., 2018; Lewis \& Westlund, 2015; Westlund, 2011; Westlund \& Krumsvik, 2014), the newsworkers at ST reported increased interaction and interdepartmental collaboration. They also demonstrated greater acceptance of innovation driven by peripheral players. However, as the metaphorical walls that demarcate professional boundaries are lowered, three tension points surface. The first is the 'language gap,' seen in divergent realities of working practices between coders and journalists. The second relates to the disparate perspectives between editorial and commercial departments, and among journalists, in reaching a consensus on definitive indicators to measure online story performance. The third point involves the murkiness surrounding 'ownership,' or what Shereen (commercial manager) called "communication alignment," when it comes to innovation that involves interdepartmental collaborations. In all three points, we argue that boundary negotiations which impact interdisciplinary collaboration demanded by the evolving newsroom would benefit from multiskilled workers, such as those described by Charissa (interactive digital journalist) and Elspeth (reporter) as "bridges." The increasing importance of peripheral players to the field of journalism may on the one hand be seen by traditional actors as a boundary incursion. On the other hand, as evidenced by our study, these incursions have given rise to hybrid roles within news organisations-new agents of change who possess skills to connect divergent professional fields and serve as linchpins for cross-functional arrangements, and possibly pave the path of innovation for the future of journalism (see also Cherubini, 2017).

\subsection{Proximity and Peripheral Players}

Based on the requirement for collaboration and bridging observed in the interviews as revealed by both its presence and its absence, we argue that proximity of peripheral players is a key factor in the appropriation of innovation. In Bourdelian terms (Vos, Craft, \& Ashley, 2012), those making incursions into the field, such as the video team, show a greater understanding of a shared goal than those who are already in the field, such as senior newsworkers. Alternatively, the same group can be viewed in different ways depending on the sense of proximity: For some reporters, coders and developers are unknown, invisible, working in the backroom; while for others they are a welcome addition who can present their stories to advantage.

This article's contribution is to propose four forms of proximity as a means to operationalise the impact of innovation from peripheral players into news organisations. The first is physical proximity. When developers, coders, and analysts were in separate departments, their work was less accepted by journalists; but once they were placed together in teams, their contributions became appropriated into everyday practice-to a greater or lesser extent depending on circumstances related to temporal, professional, and control proximity (discussed below). Physical proximity can build an easier working relationship and was initially seen when the teams were separate and did not feel a sense of collaboration. Wendy (web developer), for example, said that when artists sit alongside her team-a case of two intralopers collaborating - a shared understanding developed. 
Explicit interlopers such as bloggers, by contrast, who operate well outside the newsroom, are less welcomed into the conversation; they are characterised as a resource, not a collaborator.

The second is temporal proximity: The more time the newsworkers and peripheral players spent interacting, the likelier they were to understand each other's perspectives and to internalise them into their own work. Elspeth (reporter) said that spending time with the graphics teams gave her respect for them. Further, she and Aurora (reporter), both said that they do not have the time to think of creative ways of presenting their stories online, so the time element is handed over to the peripheral players to fulfil that role.

The third is professional proximity. Here, the goals of the work process are broadly shared, such as the pursuit of reader interests, for example, or of reader-driven income into the company. Professional proximity is most clearly observable when it is absent. Elspeth (reporter) found it "problematic" that journalists are involved with marketing, being paid to work on projects which have commercial benefits at the expense of editorial credibility, while Susannah and Lisa (reporters) accepted it as a necessity. A clash of professional cultures goes both ways, and Wendy (web developer) described how hard it was for journalists to imagine what her work involved. Web developers live in a constant state of innovation while traditional journalists are more concerned with tried and tested norms. They resist innovation because it deviates from their own working practice, and they seem to not have accepted that this is one of their new norms. Technology has innovation at its heart; journalism has consistency at its heart. This is a key barrier to normalisation of innovation into journalism. In some situations, however, innovation is not appropriated when the professional goals of the two groups (incumbent and innovator) are at odds. Elspeth (reporter) was uncomfortable that her colleagues are asked to help the marketing team by creating content for advertisers; yet at the same time she recognises that when such sponsored content adds value for the reader, it conforms to her journalistic norms.

The fourth is control proximity. This can occur when both groups acknowledge the authority of one group, allowing one side to take control; or when both groups recognise the authority of a third, most frequently management. In both cases, control allows for proximity to occur by setting clear lines of engagement. Wendy (web developer) and Shereen (commercial manager) both highlighted that innovation is often driven by editorial departments, while Gary (digital editor) stressed the importance of clarifying project ownership. Evidently, whoever is in control is less important than the fact that some form of authority is established. Moreover, integration of interlopers is not necessarily into the newsroom, but into the bigger picture of the news organisation. Thus, for example, analytics becomes appropriated into editorial business conversations about how editorial can con- tribute to the bottom line, rather than into pure editorial conversations about how to cover news.

\subsection{Limitations and Future Studies}

A limitation of this study is the small group of interviewees, who were nevertheless selected to give multiple viewpoints. Different interviewees are likely to give different perspectives, and the data is presented as illustrative rather than definitive. Further, it is worth noting that, while there is a clear impetus to innovate, innovation is not the be-all and end-all. "Where I am right now in my current role, it's still focused on putting out the paper day to day," said Nicholas (section editor). In pursuing what is novel, research runs a risk of allocating it disproportionate significance.

This study takes the theoretical models of AMI and journalistic strangers, fleshes them out with empirical illustrations, and subsequently proposes that they can be profitably examined through the abstract lens of proximity. Future empirical research would operationalise different forms of proximity, studying the appropriation of innovation vis-à-vis the three types of journalistic strangers (Holton \& Belair-Gagnon, 2018) and the three groups in the AMI model (Westlund \& Lewis, 2014). Besides making a theoretical contribution, the concept of proximity also benefits the practice of journalism. Media managers would consider each form of proximity as they encourage cross-function collaborations; for instance, newsroom integration and formalised processes for organisation-wide cooperation facilitates physical and temporal proximity. However, control proximity which delineates lines of authority and ownership in innovation is equally pertinent. Professional proximity, then, represents a high-hanging fruit for media managers as they attempt to align divergent ideals among diverse social actors with distinct professional backgrounds.

Another concept for future exploration is that of hybridity. Creating a division between traditional and non-traditional journalists; and between those on the periphery and those at the core implies dichotomies. Frequently, assimilation of innovation also demands hybridity. Traditional journalists must learn new skills, whether willingly or unwillingly. Two analogies characterise peripheral players driving innovation in the newsroom: They may be seen as immigrants arriving in a fixed society which will change to accommodate them just as they change to fit in with existing mores; or they may be something closer to Homo sapiens encroaching on territory inhabited by Homo neanderthalensis-which did not end well for the less innovative species.

\section{Acknowledgments}

We are grateful to the editors of this thematic issue and the reviewers for their invaluable comments and feedback on earlier versions of this article. We also thank the journal for supporting our work. 


\section{Conflict of Interests}

The authors declare no conflict of interests.

\section{References}

Baack, S. (2018). Practically engaged: The entanglements between data journalism and civic tech. Digital Journalism, 6(6), 673-692.

Babbie, E. (2011). The basics of social research. Belmont, CA: Wadsworth.

Belair-Gagnon, V., \& Holton, A. E. (2018). Boundary work, interloper media, and analytics in newsrooms. Digital Journalism, 6(4), 492-508.

Bruns, A. (2014). Media innovations, user innovations, societal innovations. The Journal of Media Innovations, 1(1), 13-27.

Carroll, J., Howard, S., Peck, J., \& Murphy, J. (2003). From adoption to use: The process of appropriating a mobile phone. Australasian Journal of Information Systems, 10(2), 38-48.

Cherubini, F. (2017). The rise of bridge roles in news organizations. Nieman Journalism Lab. Retrieved from https://www.niemanlab.org/2017/12/the-riseof-bridge-roles-in-news-organizations

Chua, S., \& Westlund, O. (2019). Audience-centric engagement, collaboration culture and platform counterbalancing: A longitudinal study of ongoing sensemaking of emerging technologies. Media and Communication, 7(1), 153-165.

Cornia, A., Sehl, A., \& Nielsen, R. K. (2018). 'We no longer live in a time of separation': A comparative analysis of how editorial and commercial integration became a norm. Journalism. Advance online publication. https://doi.org/10.1177/1464884918779919

Duffy, A., Tandoc, E. C., Jr., \& Ling, R. (2018). Frankenstein journalism. Information, Communication \& Society, 21(10), 1354-1368.

Eldridge, S. A., II. (2018). Online journalism from the periphery: Interloper media and the journalistic field. London: Routledge.

Fontana, A., \& Frey, J. H. (2005). The interview: From neutral stance to political involvement. In N. K. Denzin \& Y. S. Lincoln (Eds.), Handbook of qualitative research (pp. 301-316). Thousand Oaks, CA: Sage.

Holton, A. E., \& Belair-Gagnon, V. (2018). Strangers to the game? Interlopers, intralopers, and shifting news production. Media and Communication, 6(4), 70-78.

Krumsvik, A. H. (2018). Redefining user involvement in digital news media. Journalism Practice, 12(1), 19-31.

Krumsvik, A. H., Milan, S., Bhroin, N. N., \& Storsul, T. (2019). Making (sense of) media innovations. In M. Deuze \& M. Prenger (Eds.), Making media: Production, practices and professions (pp. 193-205). Amsterdam: Amsterdam University Press.

Lewis, S. C., \& Usher, N. (2013). Open source and journalism: Toward new frameworks for imagining news in- novation. Media, Culture \& Society, 35(5), 602-619.

Lewis, S. C., \& Westlund, O. (2015). Actors, actants, audiences, and activities in cross-media news work: A matrix and a research agenda. Digital Journalism, 3(1), 19-37.

Lowrey, W. (2012). Journalism innovation and the ecology of news production: Institutional tendencies. Journalism and Communication Monographs, 14(4), 214-287.

Lowrey, W., \& Gade, P. J. (2012). Changing the news: The forces shaping journalism in uncertain times. New York, NY: Routledge.

MacGregor, P. (2014). Siren song or path to salvation? Interpreting the visions of web technology at a UK regional newspaper in crisis, 2006-2011. Convergence, 20(2), 157-175.

Micó, J. L., Masip, P., \& Domingo, D. (2013). To wish impossible things: Convergence as a process of diffusion of innovations in an actor-network. International Communication Gazette, 75(1), 118-137.

Mitchelstein, E., \& Boczkowski, P. J. (2009). Between tradition and change. Journalism, 10(5), 562-586.

Nielsen, R. K. (2012). How newspapers began to blog: Recognizing the role of technologists in old media organizations' development of new media technologies. Information Communication \& Society, 15(6), 959-978.

Nielsen, R. K., Cornia, A., \& Kalogeropoulos, A. (2016). Challenges and opportunities for news media and journalism in an increasingly digital, mobile, and social media environment. Oxford: Reuters Institute for the Study of Journalism.

Paulussen, S. (2016). Innovation in the newsroom. In T. Witschge, C. W. Anderson, D. Domingo, \& A. Hermida (Eds.), The Sage handbook of digital journalism (pp. 192-206). London: Sage.

Pavlik, J. V. (2013). Innovation and the future of journalism. Digital Journalism, 1(2), 181-193.

Polit, D., \& Beck, C. (2003). Nursing research: Principles and methods (7th ed.). Philadelphia, PA: Lippincott Williams \& Wilkins.

Posetti, J. (2018). Time to step away from the 'bright, shiny things'? Towards a sustainable model of journalism innovation in an era of perpetual change. Oxford: Reuters Institute for the Study of Journalism.

Rule, P., \& John, V. M. (2015). A necessary dialogue: Theory in case study research. International Journal of Qualitative Methods. Advance online publication. https://doi.org/10.1177/1609406915611575

Schmitz Weiss, A., \& Domingo, D. (2010). Innovation processes in online newsrooms as actor-networks and communities of practice. New Media and Society, 12(7), 1156-1171.

Singer, J. B. (2005). The political j-blogger: 'Normalizing' a new media form to fit old norms and practices. Journalism, 6(2), 173-198.

Slappendel, C. (1996). Perspectives on innovation in organizations. Organization Studies, 17(1), 107-129. 
Steensen, S. (2009). What's stopping them? Towards a grounded theory of innovation in online journalism. Journalism Studies, 10(6), 821-836.

Tandoc, E. C., Jr., \& Oh, S.-K. (2017). Small departures, big continuities? Norms, values, and routines in The Guardian's big data journalism. Journalism Studies, 18(8), 997-1015.

Tandoc, E. C., Jr., \& Thomas, R. J. (2015). The ethics of web analytics. Digital Journalism, 3(2), 243-258.

Utterback, J. (2004). The dynamics of innovation. Educause Review, 2004(January/February), 42-51.

Vos, T. P., Craft, S., \& Ashley, S. (2012). New media, old criticism: Bloggers' press criticism and the journalistic field. Journalism, 13(7), 850-868.

Vos, T. P., \& Ferrucci, P. (2018). Who am I? Perceptions of digital journalists' professional identity. In S. A. Eldridge II \& B. Franklin (Eds.), The Routledge handbook of developments in digital journalism studies (pp. 40-52). New York, NY: Routledge.

Waldenström, A., Wiik, J., \& Andersson, U. (2019).
Conditional autonomy. Journalism Practice, 13(4), 493-508.

Westlund, O. (2011). Cross-media news work: Sensemaking of the mobile media (r)evolution (Unpublished Doctoral dissertation). University of Gothenburg, Gothenburg, Sweden.

Westlund, O., \& Krumsvik, A. (2014). Perceptions of intraorganizational collaboration and media workers' interests in media innovations. The Journal of Media Innovations, 1(2), 52-74.

Westlund, O., \& Lewis, S. C. (2014). Agents of media innovations: Actors, actants, and audiences. The Journal of Media Innovations, 1(2), 10-35.

Yap, L. (2017, September 19). Singapore press market value falls behind New York Times. Bloomberg. Retrieved from https://www.bloomberg.com/news/ articles/2017-09-19/singapore-press-loses-claimof-being-bigger-than-new-york-times

Yin, R. K. (2018). Case study research: Design and methods (6th ed.). Thousand Oaks, CA: Sage.

\section{About the Authors}

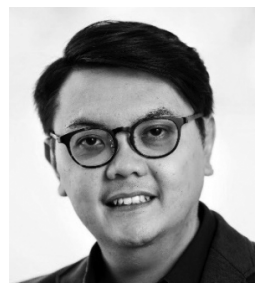

Sherwin Chua is a PhD Candidate at the Department of Journalism, Media and Communication, University of Gothenburg, Sweden. His research focuses on the intersection of media innovation and journalism practice. He holds a MA in Mass Communication from Nanyang Technological University, Singapore, and a BA from National University of Singapore. Chua is also a Freelance Journalist who covers digital transformations occurring in journalism. His articles have been published by Nieman Journalism Lab, WAN-IFRA (Asia Pacific) and The Splice Newsroom. He was a former journalist in news media and publishing, and taught journalism and mass communication-related courses at a polytechnic in Singapore.

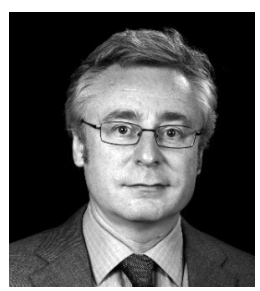

Andrew Duffy (PhD, National University of Singapore) is an Assistant Professor at the Wee Kim Wee School of Communication and Information, Nanyang Technological University. Previously a lifestyle and news journalist and editor, his research interests include the interface between mobility and the media as it relates to news journalism, and between the media and mobility as it relates to travel. His current research focuses on how news is shared on mobile media devices and its effects on society. His work has been published in Journalism, Digital Journalism, Journalism Studies, Information, Communication \& Society, and Media, Culture \& Society, among others. 